\title{
The evolution of an ancient metazoan biomineralization strategy was supported by a horizontal gene transfer
}

Daniel J. Jackson

CRC Geobiology; Georg-August University of Göttingen; Göttingen, Germany

Key words: horizontal gene transfer, lateral gene transfer, metazoa, evolution, biomineralization, cambrian, gene expression, gene regulation

Submitted: 09/01/11

Revised: 09/11/11

Accepted: 09/13/11

http//:dx.doi.org/10.4161/mge.1.3.18067

Correspondence to: Daniel J. Jackson;

Email:djackso@uni-goettingen.de

Addendum to: Jackson DJ, Macis L, Reitner J, Wörheide $G$. A horizontal gene transfer supported the evolution of an early metazoan biomineralization strategy. BMC Evol Biol 2011; 11:238; DOI:10.1186/1471-2148-11-238; PMID:21838889.
$\mathrm{T}$

The molecular mechanisms that generate morphological novelty are of great interest to evolutionary biologists because these are the processes that can explain how the diversity of life on earth arose. With advances in sequencing technologies, the high-throughput analysis and comparison of entire genomes is now possible. Bioinformatic mining of such genome-wide data sets often includes a search for horizontal gene transfers (HGTs) as these events can provide exciting insight into how morphological, or physiological novelties may have arisen. A recent paper by Jackson et al. ${ }^{1}$ demonstrates that a HGT into the genome of the sponge Astrosclera willeyana likely supported the evolution of this animal's biomineralization strategy. This HGT, which occurred deep in time, was perhaps a key event in the evolution of this animal's body form and would not have been detected by certain in silico methods commonly used to screen large data sets.

A fully resolved and consensual 'tree of metazoan life' is within the reach of evolutionary biologists. $^{2-4}$ In order to robustly resolve critical early nodes on this tree some taxonomic groups need better representation, ${ }^{5}$ nonetheless these are exciting times for those whom wish to understand how complex life evolved. This is because such a tree would allow us to more accurately reconstruct the long extinct ancestors of key animal groups, and with appropriate calibration data, to know when such ancestors lived. This goal is being brought closer by rapid advances in sequencing technologies which allow researchers to sample the genomic contents of non-model organisms at a fraction of the cost of a few years ago. ${ }^{6}$ By using genome-scale data sets in these phylogenetic analyses it is hoped that the problems associated with reconstructing deep evolutionary relationships can be ameliorated. ${ }^{2}$ Concomitant with these sequencing advances is a rapidly growing list of various mobile genetic elements (MGEs) that can be found within metazoan genomes. For example, transposable elements (TEs) that can propagate themselves within ${ }^{7}$ and between ${ }^{8,9}$ genomes, viruses that can integrate themselves into host genomes, ${ }^{10}$ and non-TE derived coding elements that have migrated between genomes. ${ }^{11,12}$ While the original paradigm that TE derived MGEs are 'junk' DNA has been dispelled, ${ }^{13}$ the functions that such DNA are being demonstrated to have are startling. A beautiful example of this in relation to the evolution of morphological novelty was provided by Sasaki et al. who demonstrated that two particular loci of the 'AmnSINE' enhance the expression of genes important for the development of the mammalian forebrain (FGF8 and SATB2). It is thought that such shuffling of TEs within and between genomes can support the evolution of novel gene regulatory systems. ${ }^{13}$ Examples of HGT delivering functionally expressed coding DNA into metazoan nuclear genomes are far rarer (cases of such HGT between prokaryotes and unicellular eukaryotes abound ${ }^{15}$ ).

Jackson et al. ${ }^{1}$ recently identified a horizontally transferred gene (Spherulin) that is highly expressed by the 'living fossil' Astrosclera willeyana. The evidence used to support the claim of HGT from 


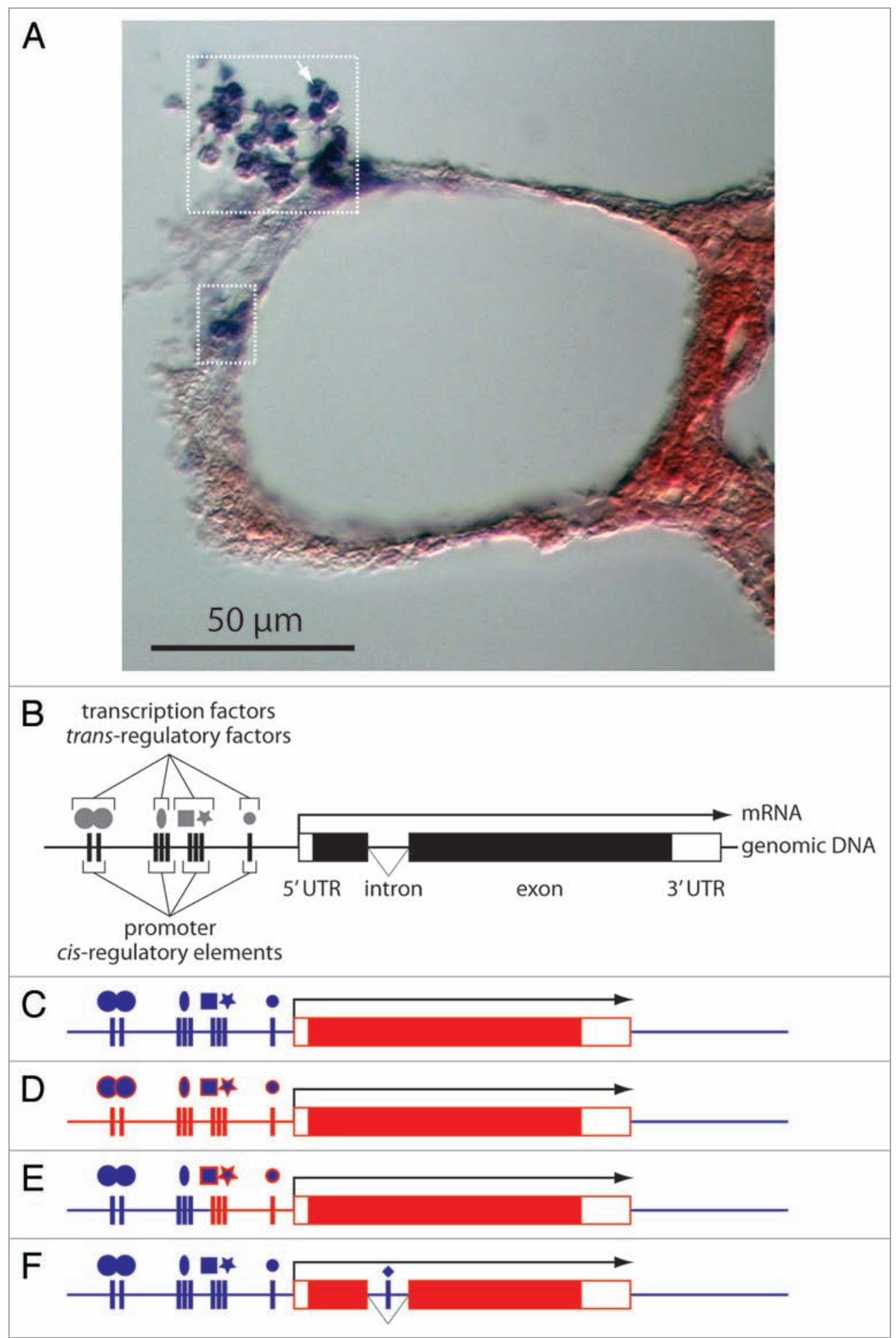

Figure 1. For figure legend, see page 244.

a bacterium into the $A$. willeyana genome was based on extensive homology searches of whole genomes from more than 270 uni- and multi-cellular eukaryotes. While these searches yielded no positive results, homology searches of prokaryotic genomes produced several significant hits across the proteobacteria. The possibility that Spherulin was unintentionally isolated from commensal proteobacteria, and is not an $A$. willeyana gene, was ruled out by several lines of evidence including spatial expression of Spherulin mRNA transcripts (Fig. 1A). Given the highly specific spatial expression pattern of the Spherulin gene and the localization of the corresponding protein within mature calcified spherulites, the authors suggest 
Figure 1 (See previous page). HGTs of transcribed DNA need to be delivered with, or recruit appropriate regulatory elements. (A) The horizontally transferred gene Awi-Spherulin is exclusively and highly expressed in a subset of $A$. willeyana's cells, those that secrete calcified spherulites.' A histological section of $A$. willeyana reveals Awi-Spherulin positive cells (within dashed boxes-an individual cell is indicated by the arrow) following in situ hybridization against the transcribed Awi-Spherulin mRNA. Other sponge cells (stained red) are devoid of Spherulin transcripts. The spatial and temporal specificity of Awi-Spherulin expression is governed by the cis- and trans-regulatory elements associated with the Awi-Spherulin gene. (B) A schematic representation of a eukaryotic gene and the associated trans-regulatory elements (transcription factors). (C-F) One, or a combination of several possible scenarios regarding the regulation of Awi-Spherulin expression must have occurred following the HGT that established Spherulin in the $A$. willeyana genome. Red elements represent horizontally transferred exogenous DNA, blue elements indicate $A$. willeyana endogenous molecules. The most simplistic scenarios are: (C) Spherulin was integrated into a genomic locus that already possessed the cis- and trans-regulatory elements necessary to drive the expression of Awi-Spherulin within spherulite forming cells. For example the Astrosclerin gene ${ }^{26}$ may have had these regulatory elements in place at the time of the Spherulin HGT. These elements could have been co-opted to immediately drive the expression of Awi-Spherulin within spherulite forming cells; (D) The HGT delivered the Spherulin open reading frame together with 'xeno' cis-regulatory elements (red vertical bars). These foreign cis-regulatory elements were then able to recruit $A$. willeyana transcription factors to drive the expression of Awi-Spherulin in spherulite forming cells. Such a scenario may have been expedited by recruiting evolutionary conserved homologs of the transcription factors used to regulate the 'original' expression of the bacterial homolog of Spherulin. These conserved, but $A$. willeyana specific, transcription factors are indicated as blue shapes with a red outline. Such a scenario would presumably require the action of selective forces to refine the expression of Spherulin in spherulite forming cells. (E) a combination of the above two scenarios may have occurred, with subsequent selective pressures refining the expression of Awi-Spherulin; (F) The Awi-Spherulin gene possesses a spliceosomal intron.' Introns can contain regulatory elements ${ }^{35}$ supporting the likelihood that the expression of Awi-Spherulin was modified and refined after its integration into the $A$. willeyana genome (as opposed to scenario C) through the addition of eukaryotic genetic features.

that the Spherulin gene is directly involved in the process of biomineralisation in $A$. willeyana. While HGTs that deliver exogenous DNA into metazoan genomes is of inherent interest to those interested in genome evolution, this particular case is noteworthy for several reasons.

First, according to the fossil record, the broad history of animal evolution can be described as being initially composed of an assemblage of soft-bodied forms of relatively low morphological disparity. This period is followed by an extremely rapid increase in morphological variety during the so-called Cambrian 'Explosion' 543 MYA. ${ }^{6,17}$ While the factors that contributed to this rapid radiation were likely to be many and varied, the relatively synchronous and widespread innovation of the ability to deposit mineralised structures (shells, spicules, skeletons, teeth, etc.,) is thought to be a major contributing factor to the Cambrian radiation. ${ }^{18}$ The study by Jackson et al. ${ }^{1}$ demonstrates that in the lineage of sponges leading to $A$. willeyana the evolution of the ability to biomineralise was in part supported by this HGT.

Second, there are similarities between A. willeyana's grade of organization and that of the once abundant stromatoporoids. Stromatoporoids formed extensive reefs in Palaeozoic and Mesozoic marine environments $^{19,20}$ as corals do today, and have been used to model paleoclimates. ${ }^{21,22}$ While stromatoporoids are long extinct and their phylogenetic affinities to modern taxa are uncertain, it is commonly believed that they represent an early lineage of sponges. ${ }^{23}$ Indeed models that describe their patterns of skeleton growth are based on extant sponges such as $A$. willeyana.$^{24}$ Without a clearer picture of the evolutionary relationships between the extinct stromatoporoids, $A$. willeyana and $A$. queenslandica, it is only possible to speculate, but it is tempting to suggest that some of the stromatoporoids of the Palaeozoic and Mesozoic eras may have been constructing reefs using a homolog of the horizontally transferred Spherulin gene that Jackson et al. describe. ${ }^{1}$

Third, as the earliest branching group of metazoans, ${ }^{3}$ the Porifera have a special role to play in reconstructing the last common ancestor of the Metazoa (LCAM). Traits possessed by both the Porifera and other metazoan sister groups were most likely present in the LCAM. Studies focused on the genome content of sponges can therefore provide much insight into the origins of the Metazoa. This reasoning was a key motivation behind the effort to sequence the first poriferan genome, Amphimedon queenslandica. ${ }^{25}$ To what degree the LCAM provided the genetic and molecular infrastructure required to deposit biominerals in a regulated fashion (and therefore to what degree the LCAM contributed genetically to the Cambrian mineralization event) is an active field of research. Studies focused on the genes involved in poriferan biomineralisation contribute to this open question. ${ }^{26}$ The report by Jackson et al. ${ }^{1}$ demonstrates that
A. willeyana employs at least one biomineralisation gene that was clearly not provided by the LCAM. Interestingly, Jackson et al. demonstrate that the non-calcifying A. queenslandica also possesses a genomic copy of Spherulin, indicating that a common ancestor of $A$. queenslandica and $A$. willeyana was subject to the Spherulin HGT event.

One question that is raised in considering the Spherulin HGT is that of gene regulation (Fig. 1). HGTs that deliver DNA that is to be transcribed within a novel genomic context must either bring relevant promoter sequence with them, or be delivered to a genomic locus that is able to drive the transcription of the exogenous DNA. If a HGT delivers an entire gene (i.e., promoter + coding DNA) into a foreign genome, then presumably the expression pattern of the new gene will be spatially and temporally refined by selective forces if that gene product is to persist by being of functional relevance to the host. HGTs that deliver coding DNA devoid of cis-regulatory material must recruit promoters from the genomic repertoire of the host. The resulting expression pattern may be immediately appropriate for the new gene (Fig. 1C), or will also need to be evolutionarily refined. The study by Jackson et al. does not address these issues, but highlights a line of investigation for Spherulin and similar HGTs that may further explain how the horizontal transfer of coding genes can generate morphological novelties. 
Most sponges harbour extensive communities of bacteria, making them natural incubators for HGT events both between the microbial residents, and the host genome. The fact that sponges have long had these associations with prokaryotes increases the likelihood and number of such events. Furthermore, the fact that sponges do not sequester germline cells as more complex animals do (i.e., sponges do not have ovaries or testes) significantly increases the chances that an HGT event within a sponge cell will be passed on to a proportion of the sponge's progeny. For these reasons it is likely that sponges will display a higher frequency of HGTs derived from prokaryotic material than their eumetazoan relatives. This prediction requires the sequencing and accurate analysis and annotation of additional poriferan genomes.

One of the interesting features of the Spherulin HGT is that it took place so long ago, at the very latest when the last common ancestor of $A$. queenslandica and A. willeyana existed, between 220-265 MYA (Reitner pers. comm.). ${ }^{27-29}$ HGTs that occur deep in time are potentially of great interest to evolutionary biologists interested in cladogenic events because they can potentially make previously uninhabitable ecological niches accessible within a relatively short period of evolutionary time. ${ }^{30}$ For example, nematodes that parasitize plant tissues invade the roots of the host through the action of cell wall degrading enzymes that were horizontally transferred from a variety of bacterial sources. ${ }^{31}$ The further back in time such novel-trait-conferring HGTs take place, the more time morphological disparity and diversity have to evolve within the descendants of the recipient organism. The problem with deep time HGTs is that they are usually more difficult to detect. This is because two of the main methods used to detect HGTs in large data sets (phylogenetic incongruence and composition based analyses such as codon usage) rely on the maintenance of a phylogenetic signal in the transferred gene. Furthermore, there is evidence that successfully transferred genes often have codon usage biases pre-adapted to those of the host, rendering composition based methods of HGT detection ineffective. ${ }^{32}$
Additionally, given enough time, such phylogenetically informative signals can be erased. This indeed was the case for the Spherulin gene within the $A$. willeyana genome. Other approaches, such as identifying features unique to eukaryotic genes (such as the presence of spliceosomal introns and polyadenylation signals), and the phylogenetic distribution of the gene, ${ }^{33,34}$ can overcome these difficulties.

The Spherulin HGT is a clear example of the transfer of genetic material from a prokaryote into a metazoan genome. This example joins the short (relative to prokaryote-prokaryote transfers) but growing list of horizontally transferred genes that are actively expressed within the nucleus of the recipient metazoan genome. The neo-function of the Awi-Spherulin gene product (if it differs at all from its ancestral prokaryotic function) is likely to be of significance when considering the evolution of the capacity to biomineralise in the lineage leading to $A$. willeyana, a capacity of relevance to our understanding of the Cambrian radiation. Investigating the evolutionary history and functions of the many un-annotated genes found in early branching metazoan genomes is likely to reveal more examples of HGT that confer morphological or physiological novelties. Mapping these HGTs onto a robust tree of life will enrich our understanding of the events and processes that accompanied the evolution and diversification of multicellular animal life.

\section{Acknowledgments}

Many thanks to members of the D.J.J. group who discussed and improved this text. This work was supported by Deutsche Forschungsgemeinschaft (DFG) funding to D.J.J. through the CRC for Geobiology and the German Excellence Initiative.

\section{References}

1. Jackson DJ, Macis L, Reitner J, Worheide G. A horizontal gene transfer supported the evolution of an early metazoan biomineralization strategy. BMC Evol Biol 2011; 11:238; PMID:21838889; http://dx.doi. org/10.1186/1471-2148-11-238

2. Philippe H, Derelle R, Lopez P, Pick K, Borchiellini C, Boury-Esnault N, et al. Phylogenomics revives traditional views on deep animal relationships. Curr Biol 2009; 19:706-12; PMID:19345102; http:// dx.doi.org/10.1016/j.cub.2009.02.052

3. Pick KS, Hervé P, Fabian S, Erpenbeck D, Jackson DJ, Wrede $\mathrm{P}$, et al. Improved phylogenomic taxon sampling noticeably affects non-bilaterian relationships. Mol Biol Evol 2010; 27:1983-7; PMID:20378579; http://dx.doi.org/10.1093/molbev/msq089
4. Dunn CWD, Hejnol A, Matus DQ, Pang K, Browne WE, Smith SA, et al. Broad phylogenomic sampling improves resolution of the animal tree of life. Nature 2008; 452:745-9; PMID:18322464; http://dx.doi. org/10.1038/nature06614

5. Philippe H, Brinkmann H, Lavrov DV, Littlewood DTJ, Manuel M, Worheide G, et al. Resolving Difficult Phylogenetic Questions: Why More Sequences Are Not Enough. PLoS Biol 2011; 9:1000602; PMID:21423652; http://dx.doi. org/10.1371/journal.pbio.1000602

6. Telford MJ, Copley RR. Improving animal phylogenies with genomic data. Trends Genet 2011; 27:186 95; PMID:21414681; http://dx.doi.org/10.1016/j. tig. 2011.02.003

7. Mikkelsen TS, Wakefield MJ, Aken B, Amemiya CT, Chang JL, Duke S, et al. Genome of the marsupial Monodelphis domestica reveals innovation in non-coding sequences. Nature 2007; 447:16777; PMID:17495919; http://dx.doi.org/10.1038/ nature 05805

8. Schaack S, Gilbert C, Feschotte C. Promiscuous DNA: horizontal transfer of transposable elements and why it matters for eukaryotic evolution. Trends Ecol Evol 2010; 25:537-46; PMID:20591532; http:// dx.doi.org/10.1016/j.tree.2010.06.001

9. Novick P, Smith J, Ray D, Boissinot S. Independent and parallel lateral transfer of DNA transposons in tetrapod genomes. Gene 2010; 449:8594; PMID:19747963; http://dx.doi.org/10.1016/j. gene.2009.08.017

10. Geuking MB, Weber J, Dewannieux M, Gorelik E, Heidmann T, Hengartner $\mathrm{H}$, et al. Recombination of retrotransposon and exogenous RNA virus results in nonretroviral cDNA integration. Science 2009; 323:393-6; PMID:19150848; http://dx.doi. org/10.1126/science.1167375

11. Gladyshev EA, Meselson M, Arkhipova IR. Massive horizontal gene transfer in bdelloid rotifers. Science 2008; 320:1210-3; PMID:18511688; http://dx.doi. org/10.1126/science.1156407

12. Mayer WE, Schuster LN, Bartelmes G, Dieterich C, Sommer RJ. Horizontal gene transfer of microbial cellulases into nematode genomes is associated with functional assimilation and gene turnover. BMC Evol Biol 2011; 11:13; PMID:21232122; http://dx.doi. org/10.1186/1471-2148-11-3

13. Feschotte C. Transposable elements and the evolution of regulatory networks. Nat Rev Genet 2008; 9:397405; PMID:18368054; http://dx.doi.org/10.1038/ nrg2337

14. Sasaki T, Nishihara H, Hirakawa M, Fujimura K, Tanaka M, Kokubo N, et al. Possible involvement of SINEs in mammalian brain formation. Proc Natl Acad Sci USA 2008; 105:4220-5; PMID:18334644; http://dx.doi.org/10.1073/pnas.0709398105

15. Andersson JO. Gene transfer and diversification of microbial eukaryotes. Annu Rev Microbiol 2009; 63:177-93; PMID:19575565; http://dx.doi org/10.1146/annurev.micro.091208.073203

16. Marshall CR. Explaining the Cambrian "Explosion" of animals. Annu Rev Earth Planet Sci 2006; 34:355-84; http://dx.doi.org/10.1146/annurev. earth.33.031504.103001

17. Conway Morris S. Darwin's dilemma: the realities of the Cambrian 'explosion'. Philosophical Transactions of the Royal Society B. Philos Trans R Soc Lond B Biol Sci 2006; 361:1069-83; PMID:16754615; http://dx.doi.org/10.1098/rstb.2006.1846

18. Knoll AHK. Biomineralization and Evolutionary History. Rev Min Geo 2003; 229-356

19. Sandström O, Kershaw S. Palaeobiology, ecology and distribution of stromatoporoid faunas in biostromes of the mid-Ludlow of Gotland, Sweden. Acta Palaeontol Pol 2008; 53:293-302; http://dx.doi. org/10.4202/app.2008.0210 
20. Wendt J, Kaufmann B. Middle Devonian (Givetian) coral-stromatoporoid reefs in West Sahara (Morocco). J Afr Earth Sci 2006; 44:339-50; http://dx.doi. org/10.1016/j.jafrearsci.2005.11.025

21. Kershaw S. The applications of stromatoporoid palaeobiology in palaeoenvironmental analysis. Palaeontology 1998; 41:509-44

22. Kershaw S, Brunton FR. Palaeozoic stromatoporoid taphonomy: ecologic and environmental significance. Palaeogeogr Palaeoclimatol Palaeoecol 1999; 149:313-28; http://dx.doi.org/10.1016/S00310182(98)00209-0

23. Stock CW. Stromatoporoidea 1926-2000. J Paleontol 2001; 75:1079-89; http://dx.doi.org/10.1666/0022 $3360(2001) 075<1079: \mathrm{S}>2.0 . \mathrm{CO} ; 2$

24. Stearn CW, Pickett JW. The Stromatoporoid Animal Revisited-Building the Skeleton. Lethaia 1994, 27:1-10; http://dx.doi.org/10.1111/j.1502-3931.1994 tb01547.x

25. Srivastava M, Simakov O, Chapman J, Fahey B, Gauthier MEA, Mitros T, et al. The Amphimedon queenslandica genome and the evolution of animal complexity. Nature 2010; 466:720-6; PMID:20686567; http://dx.doi.org/10.1038/ nature 09201
26. Jackson DJ, Macis L, Reitner J, Degnan BM, Wörheide G. Sponge paleogenomics reveals an ancient role for carbonic anhydrase in skeletogenesis. Science 2007; 316:1893-5; PMID:17540861; http:// dx.doi.org/10.1126/science. 1141560

27. Mostler H. Der erste Nachweis von agelasiden Schwämmen (Demospongiae) aus dem Jungpaläozoikum. Abh Geol Bundesanst 1994; 50:341-52

28. Reitner J. Coralline Spongien. Der Versuch einer phylogenetisch-taxonomischen Analyse. Berliner Geowiss Abh E 1992; 1:1-352

29. Reitner J. Early Paleozoic diversification of sponges: new data and evidences. Geologische Paläontologische Mitteilungen Innsbruck 1995; 20:335-47

30. Zhaxybayeva O, Doolittle WF. Lateral gene transfer. Curr Biol 2011; 21:242-6; PMID:21481756; http:// dx.doi.org/10.1016/j.cub.2011.01.045

31. Danchin EGJ, Rosso MN, Vieira P, de AlmeidaEngler J, Coutinho PM, Henrissat B, et al. Multiple lateral gene transfers and duplications have promoted plant parasitism ability in nematodes. Proc Natl Acad Sci USA 2010; 107:17651-6; PMID:20876108; http://dx.doi.org/10.1073/pnas.1008486107
32. Tuller T, Girshovich Y, Sella Y, Kreimer A, Freilich S, Kupiec M, et al. Association between translation efficiency and horizontal gene transfer within microbial communities. Nucleic Acids Res 2011; 39:4743-55; PMID:21343180; http://dx.doi.org/10.1093/nar/ gkr054

33. Cohen O, Pupko T. Inference and characterization of horizontally transferred gene families using stochastic mapping. Mol Biol Evol 2010; 27:703-13, PMID:19808865; http://dx.doi.org/10.1093/mol$\mathrm{bev} / \mathrm{msp} 240$

34. Cohen O, Rubinstein ND, Stern A, Gophna U, Pupko T. A likelihood framework to analyse phyletic patterns. Philos Trans R Soc Lond, B 2008; 363:3903-11; PMID:18852099; http://dx.doi. org/10.1098/rstb.2008.0177

35. Wray GA, Hahn MW, Abouheif E, Balhoff JP, Pizer $M$, Rockman MV, et al. The evolution of transcriptional regulation in eukaryotes. Mol Biol Evol 2003; 20:1377-419; PMID:12777501; http://dx.doi. org $/ 10.1093 / \mathrm{molbev} / \mathrm{msg} 140$ 